\title{
Flights of Gray Looper (Rachiplusia ou) (Noctuidae) and Soybean Looper (Chrysodeixis includens) (Noctuidae) in Southeast Missouri Soybean
}

\author{
Moneen M. Jones, Jessica L. Duckworth \\ Department of Plant Sciences, University of Missouri, Entomology Department, USA
}

Copyright $(\mathrm{C} 2017$ by authors, all rights reserved. Authors agree that this article remains permanently open access under the terms of the Creative Commons Attribution License 4.0 International License

\begin{abstract}
Noctuid moths include economic species of importance such as the soybean podworm, black cutworm, soybean looper, and fall armyworm. The gray looper feeds on a wide variety of low-growing plants including tobacco, soybean, cotton, clover, and common wheat. Soybean looper can likewise be found in soybean and cotton. To monitor the flights and numbers of gray and soybean loopers in Southeast Missouri, funnel traps were baited with Autographa gamma or Pseudoplusia includens lures and dispensed on 1 May 2015 in 8 randomly selected soybean fields. Traps were monitored weekly (1 May - 1 Oct 2015). Degree days began at biofix, and a single sin method with a lower threshold of $15^{\circ}$ was used to calculate accumulative degrees days. Temperature data was obtained from NOAA. Each peak flight was assigned accumulative number of degree days. Degree days for the current soybean looper model (egg to adult, $435 \mathrm{dd}$ ) were compared with estimated models for gray and soybean loopers. These models were developed by averaging accumulated degree days between counties for peaks $1-4(204,496,937$, and 1527 degree-days, gray looper) and for peaks $1-5(349,641,962,1258$, and 1540 degree days, soybean looper). Soybean looper model was accurate for flights $1-3$ for gray looper. For soybean looper management, the new soybean looper model worked best for estimating future peak flights. This confirmation of model data should help growers with their insecticide application decisions.
\end{abstract}

Keywords Gray Looper, Rachiplusia ou, Phenology, Pheromone, Soybean Looper

\section{Introduction}

Noctuid moths include economic species of importance such as the soybean podworm, fall armyworm, and soybean looper. The latter, Chrysodeixis includens (Walker, [1858]), is a common and difficult to control pest for soybean in Southeast Missouri. For several decades, soybeans have been significantly defoliated by this pest. In recent years, cotton has received the same extensive damage. In 1989, 1991, and again in 1993, some cotton fields in south and central Alabama were totally defoliated in late August and early September [1]. A single larva can consume about 22 square inches of foliage. Most of this consumption occurs in the last 4 to 5 days of the larval stage [1].

The gray looper (Rachiplusia ou)(Guenée, 1852) is likewise in the Noctuidae family and has a distribution of in the United States from New York to Florida, across Texas and the Great Plains to Montana, Colorado, New Mexico, Arizona, and California. The gray looper is a general feeder on herbaceous plants. Hosts include cultivated tobacco (Nicotiana tabacum L., Solanaceae), clover (Trifolium sp., Fabaceae), common wheat (Triticum aestivum L. Poaceae) [2], cotton (Gossypium hirsutum L., Malvaceae) and soybean (Glycine max, L., Fabaceae))(Unpublished Data, Jones and Duckworth 2016). The adult moth physically resembles the Silver Y moth (Autographa gamma)( Linnaeus, 1758), and the larvae resemble soybean loopers. The prolegs are vestigial on A3 and A4 larval segments in the soybean looper and totally absent on A3 and A4 in the gray looper (personal communication, Paul Goldstein, USDA).

During the growing season of 2014, soybean loopers were especially difficult to control. Repeated sprays were necessary to reduce the pest numbers under scouting thresholds. Spray failures of this magnitude usually suggest an insect is becoming resistant to insecticides. In this case, resistance is defined as repeated failure of a labeled rate of an insecticide. However, the problem may be that an additional moth species is joining with or displacing soybean looper; a species that is more innately tolerant to these spray applications. In this case, an optimal timed spray for gray looper could help reduce the number of sprays, reduce the intensity of each future generation of moths, and directly lessen the damage to soybean and cotton. 
Sticky traps baited with pheromone specific for Noctuidae have been used for mating disruption of the Mediterranean corn borer, Sesamia nonagrioides [3] and diamondback moth, Plutella xylostella [4]; tracking adult emergence of corn earworm, Helicoverpa armigera [5], and monitoring distribution of copitarsia worm Copitarsia declora Guenée [6]. Mating disruption in cotton and soybean is currently cost prohibitive ( $\$ 125 \mathrm{~g} / \mathrm{ac}$, ISCA Technologies), but use of pheromone traps for decision of a precise application of insecticide at egg or larval stage could be cost effective by reducing number of sprays [7].

Degree days are measurements in heat units over time calculated using thresholds as boundaries for development. Insect degree day models and accumulated degree days have aided in timing insecticide spraying for red bollworm Diparopsis castanea Hampson [7], Western tent caterpillar, Malacosoma californicum and Western spruce budworm, Choristoneura occidentalis and many more insect pests [8].

The current study provides information on the densities of gray looper and soybean looper in Southeast Missouri, compares flights between the two species, and provides a preliminary degree day predictive model for use in timing insecticide sprays throughout the growing season.

\section{Material and Methods}

\subsection{Pheromone Trap Data}

To monitor the flights and numbers of gray and soybean loopers in Southeast Missouri, green plastic funnel traps (IPS-G004, Great Lakes IPM, Vestaburg, MI) baited with Autographa gamma lures, (\#AUTGAM, Alpha Scents, Inc. West Linn, OR) or Pseudoplusia includens lures (\#PSEINC, Alpha Scents, Inc. West Linn, OR). Eight fields were randomly selected. Field 1 was located on a 20.8 ha block of soybean planted May 2015 in New Madrid Co. Missouri $(36.836567 \mathrm{~N},-89.637497 \mathrm{~W})$. Field 2 was located on a 22.7 ha block of soybean planted April 2015 in Stoddard Co. Missouri (36.95548N, -89.830712). Field 3 was located on a 23.6 ha block of soybean planted April 2015 in New Madrid Co. Missouri (36.82476, $-89.5361 \mathrm{~W})$. Field 4 was located on a 24.4 ha block of soybean planted May 2015 in New Madrid Co. Missouri (36.834816, -89.611385). Field 5 was located on a 28.4 ha block of soybean planted May 2015 in Stoddard Co. Missouri (36.659479, -89.771384). Field 6 was located on a 30.0 ha block of soybean planted May 2015 in New Madrid Co. Missouri (36.66579, -89.3759981W). Field 7 was located on a 31.9 ha block of soybean planted May 2015 in Scott Co. Missouri (36.959275, -89.86225). Field 8 was located on a 77.6 ha block of soybean planted May 2015 in New Madrid Co. Missouri (36.93906, -89.677055). Standard horticultural practices for Missouri cotton were followed including irrigation and weed control by applications of herbicides. Bucket traps were dispensed on 1 May 2015 and hung on 2.44 meter bamboo poles at the edge of each randomly selected soybean field and were monitored weekly between 1 May 2015 and 1 Oct 2015. Each trap was at a minimum distance of 27.4-m from each other so as to not cause interference between lures. Pheromone lures were replaced every six weeks. The number of moths per trap per day for each species was graphed at bi-weekly intervals for each county for 2015 (Figures 1 and 2).

\subsection{Moth Degree Days}

Weekly raw data of gray looper flights were used to determine when peak flight occurred. The degree days for each peak were determined by using a degree day calculator [9] with calculations based off Zalom et al. [10]. Counts of degree days were started at biofix, which was defined as 3 days of sustained flight. A single sine method with a lower threshold of $15^{\circ}$ was used to calculate accumulative degrees days. This threshold corresponded to the lower threshold for soybean looper [11], a close relative [12]. The sine wave method was chosen because it uses both a low and high threshold and is a more precise method of calculating degree days [13]. Data for each dates high and low temperature were obtained from the national Climatic Data Center, through NOAA (https://www.ncdc.noaa.gov/cdo-web). Each peak for each generation of each moth was assigned an accumulative number of degree days that corresponded with that date.

\subsection{Comparison of Flight and Models}

The degree days for soybean looper model (egg to adult, $435 \mathrm{dd}$ ) were estimated by assuming egg, pre-pupal, pupal, and pre-ovipositional degree-day requirements were similar to those of the corn earworm. For flights with soybean looper, this would correspond to degree-days of $435,870,1305$, and 1740 for four peaks. An estimated model for soybean looper was developed by averaging accumulated degree days for peaks 1 through 5 with peak flights of Mississippi, Pemiscot, New Madrid, and Stoddard counties (Table 1). An estimated model for gray looper was also developed by averaging accumulated degree days for peaks $1-4$, and these correlated to $215,520,987$, and 1604 degree-days. Peak flights of $2-4$ for gray looper and $1-3$ for soybean looper were used for comparison as soybean looper flight occurs later in the season (i.e. 23 June). Only those counties that contained field populations with greater than 2 generations per year were included for analyses of degree days between counties. 


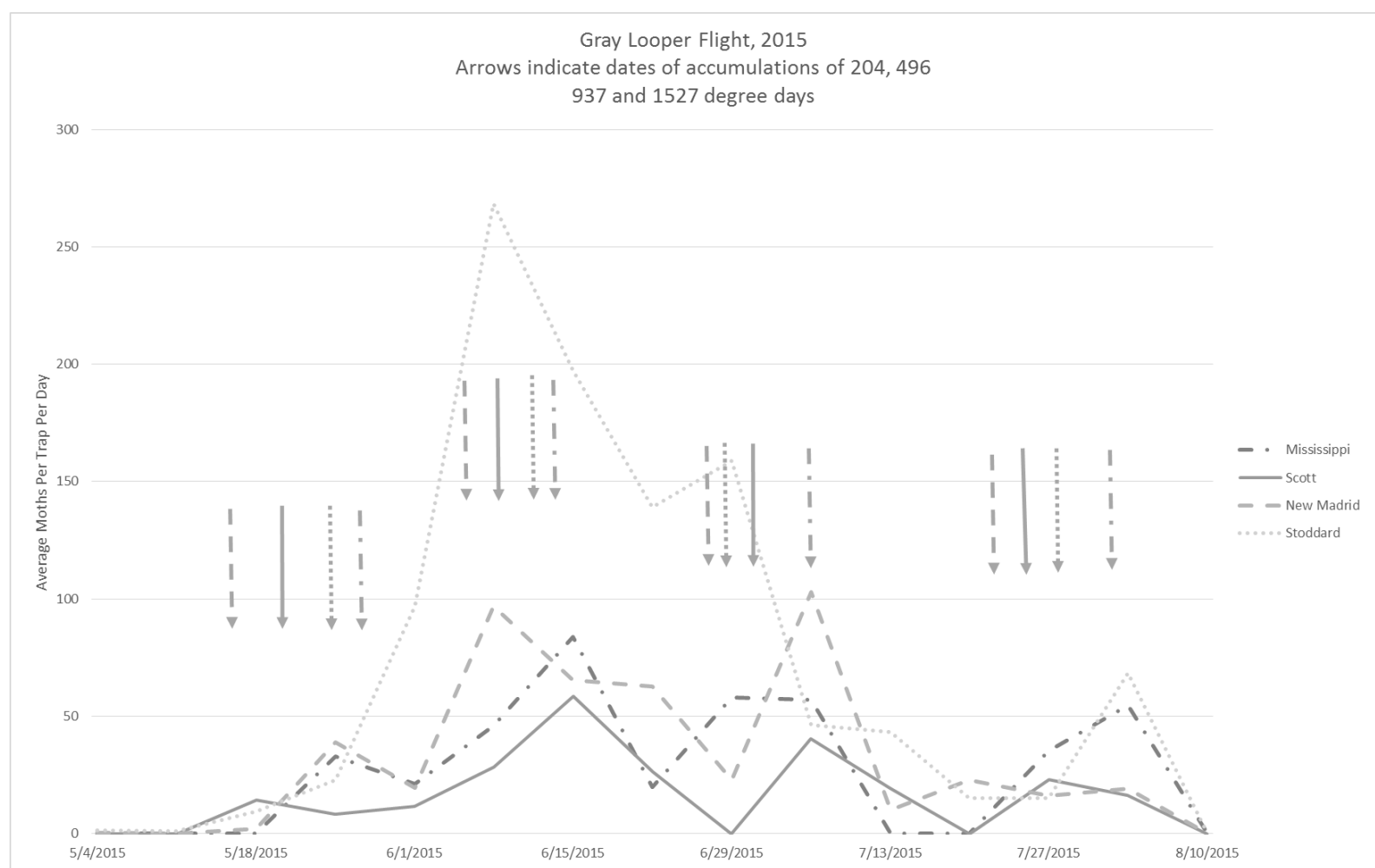

Figure 1. Moth flight graphed at 2-week intervals and arrows represent estimated generation degree days for gray looper (204dd, 496dd, 937dd, and $11527 \mathrm{dd}$ ) added to the figure. Arrows are patterned according to county and show when the accumulated degree days occurred for each peak flight.

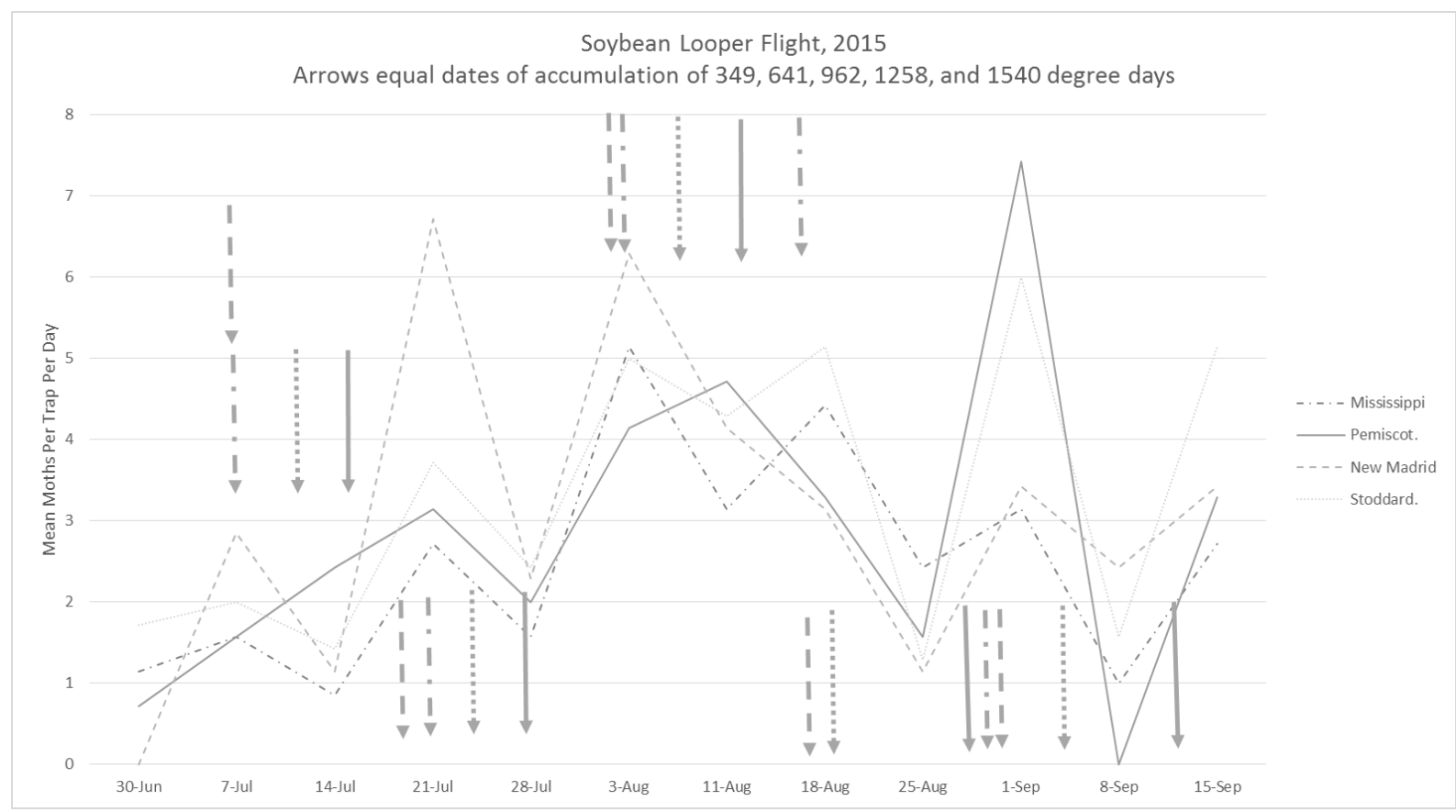

Figure 2. Moth flight graphed at 2-week intervals and arrows represent estimated generation degree days for soybean looper (435dd, $870 \mathrm{dd}, 1305 \mathrm{dd}$, and $1740 \mathrm{dd})$ added to the figure. Arrows are patterned according to county and show when those accumulated degree days occurred for each peak flight. 
Table 1. Total trap counts of gray looper in Southeast Missouri, 2015.

\begin{tabular}{|c|c|c|c|}
\hline Insect & Threshold & Degree-Days & Source \\
\hline Gray looper & $15^{\circ} \mathrm{C}$ & $\begin{array}{c}204,496,937,1527 \\
\text { (accumulative dd, by peak })\end{array}$ & Estimated $^{3}$ \\
\hline Soybean looper & $15^{\circ} \mathrm{C}$ & $435,870,1305,1740,2175$ & Correlated by flight $^{\circ}$ \\
\hline Soybean looper & $15^{\circ} \mathrm{C}$ & $\begin{array}{l}349,641,962,1258,1540 \\
\text { (accumulative dd, by peak) }\end{array}$ & \\
\hline
\end{tabular}

${ }^{1}$ Degree days associated with gray looper peak flights $1,2,3$, and 4, respectively.

${ }^{2}$ Estimated egg-adult development by assuming egg, pre-pupal pupal, and pre-ovipositional degree-day requirements were similar to those of the corn earworm. Larval degree-day requirement of 187 degree-days was calculated from Boldt et al. [14].

${ }^{3}$ Degree days associated with soybean looper peak flights of $1,2,3,4$, and 5 , respectively.

Table 2. Biofix dates for each county trap for 2015 .

\begin{tabular}{|c|c|c|c|c|c|c|}
\hline Moth & MS & Scott & NM $^{2}$ & Stodd $^{3}$ & Dunkl $^{4}$ & Pemis $^{5}$ \\
\hline Soybean Looper & 23 Jun & 23 Jun & 23 Jun & 23 Jun & 23 Jun & 30 Jun \\
\hline Gray Looper & 25 May & 18 May & 18 May & 4 May & No flight & 4 May \\
\hline
\end{tabular}

${ }^{1}$ Mississippi County

${ }^{2}$ New Madrid County

${ }^{3}$ Stoddard County

${ }^{4}$ Dunklin County

${ }^{5}$ Pemiscot County

Table 3. All county data combined for analysis of peak data. No significant differences between flight and soybean or gray looper models.

\begin{tabular}{|c|c|c|c|c|}
\hline & & \multicolumn{3}{|c|}{ Gray Looper Flight (dd + SEM) } \\
\hline & Peak 1 & Peak 2 & Peak 3 & Peak 4 \\
\hline Flight & $204.0 \pm 22.4 \mathrm{a}$ & $485.8 \pm 21.4 \mathrm{a}$ & $937.3 \pm 39.9 \mathrm{a}$ & $1527.0 \pm 22.6 \mathrm{a}$ \\
\hline GL Model & $204.0 \pm 19.4 \mathrm{a}$ & $496.0 \pm 21.4 \mathrm{a}$ & $937.0 \pm 39.9 \mathrm{a}$ & $1527.0 \pm 22.6 \mathrm{a}$ \\
\hline SL Model & $\mathrm{X}$ & $435.0 \pm 21.4 \mathrm{a}$ & $870.0 \pm 39.9 \mathrm{a}$ & $1305.0 \pm 22.6 \mathrm{~b}$ \\
\hline
\end{tabular}

ANOVAS (A): (All Counties combined, by peak) Peak 1: $\mathrm{F}=0.00$; d.f. $=1,5 \mathrm{P}=1.000$; Peak 2: $\mathrm{F}=2.32 ; \mathrm{d} . \mathrm{f}=2,9 \mathrm{P}=0.1536$ (DD); Peak 3: $\mathrm{F}=0.94$, df=2,9 $\mathrm{P}=0.4251$ (DD); Peak 4: $\mathrm{F}=32.27, \mathrm{df}=2,9 \mathrm{P}=0.0001$.

\subsection{Statistical Analysis}

For direct comparison, interpretation, and incorporation into a predictive model, cumulative catch was defined on a degree day scale. Each county was considered to be a replicate. Differences between degree days of flight and models were analyzed with an analysis of variance (anova; proc glm, proc mixed, SAS Institute [15]. Factors in the model were county, flight/model, peak/generation, and degree days. We analyzed differences in degree days between flight and models with all peaks combined, all county data combined, and all county and peaks data combined. Post hoc analyses of effects were performed using lsmeans. For peak analysis with all counties combined, only generations 2 - 4 were compared because soybean looper flight starts later in the season.

\section{Results and Discussion}

In 2015, we dispensed pheromone traps in soybean fields and monitored flight of these moth pests to determine the number of generations of each moth species per year in
Southeast Missouri. We also compared the degree days associated with each peak flight to degree days associated with a soybean development model, and two estimated flight models for each species.

Average counts for gray looper and soybean looper on a bi-weekly basis at each site are presented in Figures 1 and 2. Results are expressed as the number of moths per trap per day for the period (seven days) preceding each count. Biofix dates (dates of the first significant and sustained captures of males in traps) for soybean looper were between 23 Jun and 30 Jun and between 4 May and 25 May for gray looper (Table 2).

When all counties were combined to examine differences in peak flight for gray looper and compared to the soybean looper and gray looper models, only peak 4 flight of gray looper significantly differed between models (Table 3 ). At this flight the soybean looper model predicted moth flight +200 dd before the gray looper model. However, because most damage can be reduced and predicted by the first flight, either model (i.e. soybean or gray looper) would still benefit management of these pests in soybean or cotton. 
Table 4. All peak data combined for analysis by county. No significant differences between flight and soybean or gray looper models.

\begin{tabular}{|c|c|c|c|c|}
\hline \multicolumn{5}{|c|}{ County (dd) $+($ SEM $)$} \\
\hline Flight & Mississippi & New Madrid & Scott & Stoddard \\
\hline GL Model & $742.8 \pm 267.3 \mathrm{a}$ & $811.3 \pm 264.6 \mathrm{a}$ & $828.8 \pm 270.8 \mathrm{a}$ & $960.3 \pm 317.6 \mathrm{a}$ \\
\hline SL Model & $791.0 \pm 267.3 \mathrm{a}$ & $791.0 \pm 264.6 \mathrm{a}$ & $791.0 \pm 270.8 \mathrm{a}$ & $791.0 \pm 275.0 \mathrm{a}$ \\
\hline
\end{tabular}

ANOVAS (E): (All Peaks combined, by County) MS: $F=0.05$; d.f =2,8 P=0.9557 (DD); NM: $F=0.02, d f=2,8$ P=0.9803; $S \operatorname{cott}: F=0.02$, df=2,8 P=0.9819; Stod: $\mathrm{F}=0.08, \mathrm{df}=2,7 \mathrm{P}=0.9227$.

When peaks for gray looper and soybean looper were combined for each county, no significant difference was noted between the models and peak degree days (Tables 4, 7). Most likely, this is due to the counties surveyed being located in the same planting region (Figure 3). Due to Hopkins' bioclimatic law, [16] which states that in North America east of the Rockies, a 400-foot increase in elevation, a 4-degree change in latitude north, or a 10-degree change in longitude east will cause any given biological event to occur four days later in the spring or four days earlier in the fall, the degree days in Missouri may shift by as much as four days. Each region would need to have their own pheromone trap data and not rely on other regional accumulated degree days for decisions on spray timing of insecticides. Likewise, when all peaks and counties were combined, there were no significant differences in the average accumulated degree days between soybean and gray looper flights and either model (Tables 5, 8).

When all counties were combined to examine differences in peak flight for soybean looper and compared to the soybean looper and gray looper models, the number of degree days for peak 1 flight was significantly lower than either model. For peaks $2-5$, soybean looper flight was also significantly lower than the soybean model, but the new model using average degree days for moth flights in the 6 counties was more accurate (Table 6). At this flight the soybean looper model predicted moth flight $+200 \mathrm{dd}$ before the gray looper model. However, because most damage can be reduced and predicted by applications of insecticides following peak flight when small larvae are present, the newer model would benefit management of soybean looper.

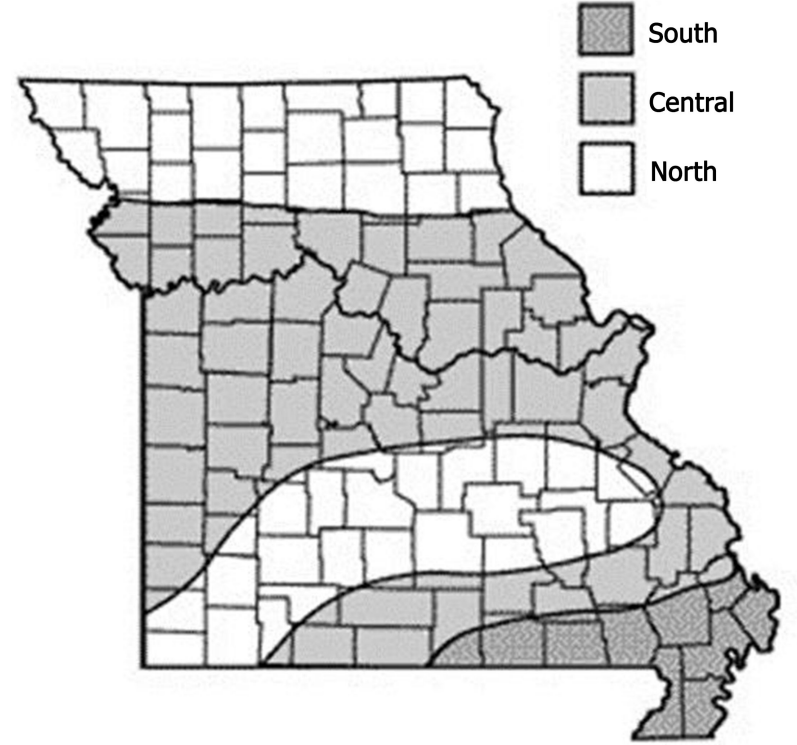

Figure 3. Map of climatic sections for Missouri according to Hopkins bioclimatic law.

Table 5. All county and peak data combined for analysis of gray looper data. No significant differences between flight and soybean or gray looper models.

\begin{tabular}{|c|c|}
\hline Flight/Model & \\
\hline & $(\mathrm{dd})+(\mathrm{SEM})$ \\
\hline Flight & $827.5 \pm 124.0 \mathrm{a}$ \\
\hline GL Model & $791.0 \pm 120.1 \mathrm{a}$ \\
\hline SL Model & $870.0 \pm 138.7 \mathrm{a}$ \\
\hline
\end{tabular}

ANOVAS (C): (All peaks and counties combined); $\mathrm{F}=0.09 ;$ d. $\mathrm{f}=2,40$, $\mathrm{P}=0.9115$ (DD 
Table 6. All county data combined for analysis of soybean looper peak data. No significant differences between flight and soybean looper models for peak 1. The new estimated models fit soybean looper flight for Peaks $2-5$.

\begin{tabular}{|c|c|c|c|c|c|}
\hline \multicolumn{6}{|c|}{ Soybean Looper Flight (dd + SEM) } \\
\hline & Peak 1 & Peak 2 & Peak 3 & Peak 4 & Peak 5 \\
\hline Flight & $\begin{array}{c}331.3 \pm \\
9.39 b\end{array}$ & $\begin{array}{c}640.5 \pm \\
10.6 b\end{array}$ & $\begin{array}{c}945.5 \pm \\
9.4 b\end{array}$ & $\begin{array}{c}1340.3 \pm \\
47.7 \mathrm{~b}\end{array}$ & $\begin{array}{c}1625.7 \pm \\
66.4 \mathrm{~b}\end{array}$ \\
\hline New Model & $\begin{array}{c}349.0 \pm \\
8.13 \mathrm{a}\end{array}$ & $\begin{array}{c}641.0 \pm \\
10.6 \mathrm{~b}\end{array}$ & $\begin{array}{c}962.0 \pm \\
9.4 \mathrm{~b}\end{array}$ & $\begin{array}{c}1258.0 \pm \\
47.7 \mathrm{~b}\end{array}$ & $\begin{array}{c}1540.0 \pm \\
57.5 \mathrm{~b}\end{array}$ \\
\hline SL Model & $\begin{array}{c}435.0 \pm \\
8.13 \mathrm{a} \\
\end{array}$ & $\begin{array}{c}870.0 \pm \\
10.6 \mathrm{a} \\
\end{array}$ & $\begin{array}{c}1305.0 \pm \\
9.4 \mathrm{a}\end{array}$ & $\begin{array}{c}1740.0 \pm \\
47.7 \mathrm{a}\end{array}$ & $\begin{array}{c}2175.0 \pm \\
81.4 \mathrm{a}\end{array}$ \\
\hline
\end{tabular}

ANOVAS (D): (All Counties combined, by peak) Peak 1: F=43.17; d.f. =2,8 P=0.0001; Peak 2: F = 155.3; d.f =2,9 P=0.0001 (DD); Peak 3: F=466.5, $\mathrm{df}=2,9 \mathrm{P}=0.0001$ (DD); Peak 4: $\mathrm{F}=29.24, \mathrm{df}=2,9 \mathrm{P}=0.0001$; Peak 5: $\mathrm{F}=21.5 ;$ d.f. $=2.6 \mathrm{P}=0.0018$.

Table 7. All peak data combined for analysis by county. No significant differences between flight and soybean looper models.

\begin{tabular}{|c|c|c|c|c|}
\hline \multicolumn{5}{|c|}{ County $(\mathrm{dd})+(\mathrm{SEM})$} \\
\hline & Mississippi & New Madrid & Pemiscot & Stoddard \\
\hline Flight & $961.8 \pm 249.3 \mathrm{a}$ & $1082.8 \pm 269.2 \mathrm{a}$ & $959.7 \pm 274.7 \mathrm{a}$ & $894.8 \pm 223.1 \mathrm{a}$ \\
\hline New Model & $950.0 \pm 249.3 \mathrm{a}$ & $950.0 \pm 269.2 \mathrm{a}$ & $950.0 \pm 212.8 \mathrm{a}$ & $950.0 \pm 223.1 \mathrm{a}$ \\
\hline SL Model & $1305.0 \pm 249.3 \mathrm{a}$ & $1305.0 \pm 269.2 \mathrm{a}$ & $1087.5 \pm 237.9 \mathrm{a}$ & $1087.5 \pm 249.4 \mathrm{a}$ \\
\hline
\end{tabular}

ANOVAS (E): (All Peaks combined, by County) MS: $F=0.65 ;$ d.f =2,12 P=0.5374 (DD); NM: $F=0.44, d f=2,12$ P=0.6517; Pemiscot: $F=0.11$, df=2,9 $\mathrm{P}=0.9006 ;$ Stod: $\mathrm{F}=0.17, \mathrm{df}=2,11 \mathrm{P}=0.8444$.

Table 8. All county and peak data combined for analysis of soybean looper data. No significant differences between flight and soybean looper model.

\begin{tabular}{|c|c|}
\hline Flight/Model & \\
\hline & $2015(\mathrm{dd})+($ SEM $)$ \\
\hline Flight & $976.4 \pm 117.4 \mathrm{a}$ \\
\hline New Model & $950.0 \pm 111.4 \mathrm{a}$ \\
\hline SL Model & $1208.3 \pm 117.4 \mathrm{a}$ \\
\hline
\end{tabular}

ANOVAS (F): (All peaks and counties combined) $\mathrm{F}=1.50$; d.f $=2,53$, $\mathrm{P}=0.2324(\mathrm{DD}$

Pheromone traps are currently monitored in these commodities to signal peak moth flight and to alert individuals to begin scouting for larvae in the fields. However, because these models fit the region so well, it is possible to predict not only future flights, but also moth density. Asaro and Berisford [17] found pheromone trap data was strongly correlated with tip moth, Rhyacionia frustrana (Comstock) density and damage. Estimated generation times in degree days will save growers time by providing pest information weeks in advance, which will benefit commercial growers with large farm operations or with those managers of multiple farms that are greater distances apart.

Data for each peak and county was not significantly different than each representative model, which suggests that either model is a good fit for Missouri topography. This outcome could be the result of the generalist eating preference of these species of moths and having the option of multiple commodities available concurrently, whereby there is no dearth of food affecting their seasonal development. However, these models are only as good as the weather data collected. In this research, we chose to use weather data from a single weather station located not necessarily close to our pheromone traps. It is possible that the resultant degree days will not mirror the actual insect development. Further north, the Glaciated Till Plains of Missouri can result in a wide variety of microclimates with its rolling hills and flat plains [18]. In these cases, individual weather stations can be used near the pheromone traps.

Although temperature is a major factor influencing moth development and phenology, other environmental factors such as row crop management may also have an effect on moth parameters of eggs, larvae, and pupae. Rotations between soybean and cotton or corn did not have an effect on degree of similarity between the models and peak flight degree days for any moth species. This result is to be expected because the moths are normally found on either host plants. Unlike wireworms and corn rootworms, crop rotation has no effect on the physiology or control of these moths.

We chose to use the sine method [19], which is one of the more detailed and accurate methods of calculating degree days. However, an alternative method can be used without use of an online calculator. The average method [(daily maximum temperature + daily minimum temperature)/2] baseline temperature, is a quick method of estimating degree days for field applications [20]. We did not use individual weather stations at each location, but chose to use county weather station data. These weather stations are commonly used for online degree day calculators (University of California (http://ipm.ucanr.edu/WEATHER/index.html) or University of Illinois

(http://www.sws.uiuc.edu/warm/pestdata/sqlchoose1.asp?pl $\mathrm{c}=$ ), and the use of local weather station data has been used for describing phenological records [21], [22].

Infestations by first generation moths rarely cause economic damage, and treatments are often not necessary. However, second and later generations are often met with multiple insecticide applications. Currently, no $B t$ treated seeds are available for soybean in the United States, and 
there are multiple sprays of insecticides each season (1-2, $\$ 12 /$ ac bollworm, fall armyworm, loopers) [23], Bill Emerine, personal communication, Crop Tech May 2017). Twenty percent of all soybeans ( $1.1 \mathrm{M}$ acres) in Missouri will be infested with soybean loopers. For control, these applications are most effective if applied at egg stage or young larvae [24].

The use of pheromone traps for monitoring flight of soybean and gray looper adults will allow for a more precise insecticide application that can significantly lower management costs. Mueller and Stern [25] showed that a properly timed insecticide treatment for Lygus nymphs was economically beneficial by reducing the number of subsequent cotton treatments. By targeting the first large spring generation, a grower will be treating the generation that would be responsible for the egg laying the remainder of the season. Teixeira et al. [26] found that a well-timed application of the insect growth regulator, methoxyfenozide, for grape berry moth Paralobesia viteana (Clemens) resulted in significantly fewer damaged berries than the treatment with phosmet. Methoxyfenozide is likewise used for control of soybean looper and is likely to reduce the negative impact on beneficial insects.

To date, Silver Y moth is not present in Missouri, but monitoring efforts could be confounded by gray looper having a propensity to be attracted to the Silver $\mathrm{Y}$ moth pheromone lure (personal observation, 2015). Between May - October of 2015, large numbers of gray looper moths were inadvertently caught in Silver Y traps dispensed in Southeast Missouri. The dual lure attractant lead to data confusion for recorded moth catch. Lures contain pheromone components in non-gram quantities (i.e. 0.000000001), and it is possible to have multiple species attracted to the same lure if the chemical components are very similar. For example, sex attractants of several symptric noctuid moths require Z-11-hexadecen-1-yl acetate and additional olefinic compounds for specific species attraction [27].

Besides pheromone similarities to other noctuids, gray looper larvae resemble that of the soybean looper. Use of pheromone traps could help determine the density of each species in a field and the probability of finding each, which is a faster way of confirming identification in the field. These traps can also be used to predict infestation levels and damage [17]. However, adults of Silver Y and gray looper appear very similar, and first flight of gray loopers in Missouri (25 May) could be confused with migrations of silver Y moths males if they occur (20 Apr 2017, [28]; 5 Jun 1996, [29]

\section{Conclusions}

The current results emphasize a novel approach of using pheromone traps and accumulated degree days for management of these moth species in Missouri. Growers should dispense pheromone traps into fields early in the season (i.e. Mar) as to not miss biofix of gray looper, which determines the accuracy of future peak flights (Agnello et al. 1993). Further research should include areas of Missouri with different topographical aspects to determine if these models still hold. An online degree day calculator for Missouri such as those at University of California (http://ipm.ucanr.edu/WEATHER/index.html) or University of Illinois

(http://www.sws.uiuc.edu/warm/pestdata/sqlchoose1.asp?pl $\mathrm{c}=$ ) would reduce the effort necessary in these calculations.

\section{REFERENCES}

[1] Smith, R.H., B. Freeman, W. Foshee. Soybean loopers: Late season foliage feeders on cotton. Alabama Cooperative Extension System. ANR-843, 1994.

[2] Eichlin, T.D., Cunningham, H.B. The Plusiinae (Lepidoptera: Noctuidae) of America north of Mexico, emphasizing genitalic and larval morphology. United States Department of Agriculture, Technical Bulletin, 1567, 1-122, 1978.

[3] Albajes, R., M. Konstantopoulou, O. Etchepare, M. Eizaguirre, B. Frerot, A. Sans, F. Krokos, A. Ameline, B. Mazomenos. Mating disruption of the corn borer Sesamia nonagrioides (Lepidoptera: Noctuidae) using sprayable formulations of pheromone. Crop Prot. 21, 217-225, 2002.

[4] Mitchell, E.R., G. Y. Hu, J. Okine, J. R. McLaughlin. Mating Disruption of Diamondback Moth (Lepidoptera: Plutellidae) and Cabbage Looper (Lepidoptera: Noctuidae) in Cabbage Using a Blend of Pheromones Emitted from the Same Dispenser. J. Entomol. Sci. 32, 120-137, 1997.

[5] Mironidis, G. Overwintering Survival and Spring Emergence of Helicoverpa armigera (Lepidoptera: Noctuidae) in Northern Greece George Environ. Entomol. 39:1068-1084, 2010 .

[6] Diaz-Gomez, O., E.A. Malo, S.A. Patino-Arrellano, J.C. Rojas. Pheromone trap for monitoring Copitarsia decolora (lepidoptera: noctuidae) activity in cruciferous crops in Mexico. Florida Entomol. 95: 602-609, 2012.

[7] Marks, R.J. Assessment of the use of sex pheromone traps to time chemical control of red bollworm, Diparopsis castanea Hampson (Lepidoptera: Noctuidae) in Malawi. Bull. Entomol. Res. 67: 575 - 587, 1977.

[8] Murray, M.S. Using degree days to time treatments for insect pests. Utah State University Extension and Utah Plant Pest Diagnostic Laboratory. IPM-05-08, 2008.

[9] Snyder, R.L. DEGDAY.xls program. University of California, Davis. http://biomet.ucdavis.edu/DegreeDays/DegDay.htm [Web accessed: May 1, 2017].

[10] Zalom, F.G., P.B. Goodell, L.T. Wilson, W.W. Barnett, and W.J. Bentley. 1983. Degree-days: The calculation and use of heat units in pest management. UC DANR Leaflet 21373

[11] Whitworth, R. J., F. L. Poston. 1979. A thermal unit accumulation system for the southwestern corn borer. Ann. Ent. Soc. Am. 72:253-255, 2005. 
[12] Lafontaine, J., D. Poole, R.W. Poole. The Moths of America North of Mexico, including Greenland. Fascicle 25.1. Noctuoidea: Noctuidae (Part): Plusiinae Published by The Wedge Entomological Research Foundation. H.H. Neunzig \& J.R. Baker (illustrator). xii + 113 p, 1991.

[13] Baskerville, G.L., P. Emin. Rapid estimation of heat accumulation from maximum and minimum temperatures. Ecology, 50:514-517, 1969.

[14] Boldt, P. E., K. D. Biever, C. M. Ignoffo. Lepidopteran Pests of Soybeans: Consumption of Soybean Foliage and Pods and De- velopment Time. J. Econ. Entomol. 68: 480-482, 1975.

[15] SAS/STAT Software, Version 9.4. by: SAS Institute Inc. Cary, NC, 2016.

[16] Hopkins, A.D. The bioclimatic law. J. Wash. Acad. Sci. 10:34-40, 1920

[17] Asaro, C., C.W. Berisford. Use of pheromone traps to predict infestation levels of the nantucket pine tip moth: Can it be done? In: Proceedings of an informal conference The Entomological Society of America, Annual Meeting, December 12-16, Atlanta, GA, eds. Berisford, C. Wayne; Grosman, D.M., p. 1-7, 1999.

[18] Nigh, T.A., W.A. Schroeder. Atlas of Missouri ecoregions. Jefferson City, MO: Missouri Dept. of Conservation, 2002.

[19] Allen, J.C. A modified sine wave method for calculating degree days. J. Environ. Entomol.5:388-396, 1976.

[20] Herms, D.A. Using degree-days and plant phenology to predict pest activity. In: V. Krischik and J. Davidson, eds. IPM (Integrated Pest Management) of Midwest Landscapes, pp. 49-59. Minnesota Agricultural Experiment Station Publication 58-07645, 316 pp, 2004.
[21] Lindsey, A.A., J.E. Newman. Use of official weather data in spring time: Temperature analysis of an Indiana phenological record. Ecology. 37:812-823, 1956.

[22] Boyer, W.D. Air temperature, heat sums, and pollen shedding phenology of longleaf pine. Ecology. 54: 420-426, 1972.

[23] Williams, M. Cotton insect losses. Mississippi State University.http://www.entomology.msstate.edu/resources/cro plosses/2016loss.asp [Accessed May 24, 2017], 2016.

[24] Bethke A., N. Fielenbach, Z. Wang, D.J. Mangelsdorf, A. Antebi. Nuclear hormone receptor regulation of microRNAs controls developmental progression. Science 324, 95-98, 2009.

[25] Mueller, W.T., V.M. Stern. Timing of pesticide treatments of safflower to prevent lygus from dispersing to cotton. J. Econ. Entomol. 67: 77-80, 1974.

[26] Teixeira, L.A. K. Mason, R. Isaacs. Control of grape berry moth (Lepidoptera: Tortricidae) in relation to oviposition phenology. J. Econ. Entomol. 102:692-698, 2009.

[27] Steck, W., E.W. Underhill, M.D. Chisholm. Attraction and inhibition in moth species responding to sex-attractant lures containing Z-11-hexadecen-1-yl acetate. J. Chem. Ecol. 3:603. Doi: 10.1007/BF00989080, 1976.

[28] Collier, R. AHDB Horticulture Pest Blog - including crop viruses.

[http://http://blogs.warwick.ac.uk/rosemarycollier/monthly/04 17/] accessed: 20 Jun 2017.

[29] Biddle, A.J. Vining peas: monitoring and control of silver Y moth (Autographa gamma). Horticultural Development Council. Pp.22.

[http://https://horticulture.ahdb.org.uk/sites/default/.../FV\%20 192\%20Final\%20Report.pdf] accessed: 20 Jun 2017, 1998. 